ARTIGO

dol https://doi.org/10.22481/rpe.v16i43.6822

\title{
EDUCAÇÃO INCLUSIVA E FORMAÇÃO DE PROFESSORES: O QUE REVELAM OS CURRÍCULOS DOS CURSOS DE LICENCIATURA?
}

\author{
INCLUSIVE EDUCATION AND TEACHER TRAINING: WHAT DO THE \\ CURRICULUMS OF UNDERGRADUATE COURSES REVEAL?
}

\begin{abstract}
EDUCACIÓN INCLUSIVA Y FORMACIÓN DOCENTE: ¿QUÉ REVELAN LOS CURRÍCULOS DE LOS CURSOS DE LICENCIATURA?
\end{abstract}

\author{
Viviane Borges Dias \\ Universidade Estadual de Santa Cruz - Brasil \\ Luciene Maria da Silva \\ Universidade do Estado da Bahia - Brasil
}

\begin{abstract}
Resumo: O discurso que fundamenta a Educação Inclusiva passa, entre outros aspectos, por uma formação docente que seja capaz de considerar as diferenças dos alunos e suas aprendizagens. Neste sentido, é interessante entender em que medida os currículos dos cursos de formação de professores têm sido configurados para permitir discussões e reflexões sobre a diversidade dos alunos. Os dados aqui apresentados são um recorte da pesquisa de doutorado intitulada Formação de Professores e Educação Inclusiva: Uma Análise à Luz da Teoria Crítica da Sociedade. Este artigo objetivou identificar e caracterizar no currículo de onze cursos de licenciatura, de uma universidade pública baiana, disciplinas relacionadas a abordagem da Educação Inclusiva. A pesquisa tem abordagem qualitativa e por meio da análise documental foram analisados os fluxogramas e Projetos Acadêmicos Curriculares (PACs) dos cursos de formação de professores. A análise de conteúdo foi a metodologia de análise de dados escolhida. O estudo evidenciou que os cursos de Ciências Biológicas, Educação Física, História e Pedagogia são os que ofertam disciplinas obrigatórias e /ou optativas relacionadas à Educação Inclusiva em seus currículos. A ausência de disciplinas que abordem a educação inclusiva nas universidades impossibilita um debate fundamental, sobretudo nas licenciaturas, visto que o número de matrículas de alunos com deficiência nas classes regulares vem crescendo significativamente.
\end{abstract}

Palavras chave: Educação Inclusiva; Currículo; Formação de professores.

\begin{abstract}
The narrative that underlies Inclusive Education goes, among other aspects, through teacher education that is capable of considering the different aspects of individual students and their learning. In this sense, it is important to understand to what extent the curriculum for teacher training has been configured to allow discussions and reflections on the diversity of the student body. The data presented herein is an excerpt from the doctoral research entitled Formation of Teachers and Inclusive Education: An Analysis Based on the Critical Theory of Society. This article aims to identify and characterize in the curriculum of eleven undergraduate courses from a public university in Bahia disciplines related to the Inclusive Education approach. The research has a qualitative approach, and through document analysis it examines the flowcharts and Academic Curricular Projects (PACs) related to the teacher training
\end{abstract}


courses. Content analysis was the chosen data analysis methodology. The study shows that Biological Sciences, Physical Education, History and Pedagogy courses are those that offer mandatory and / or optional subjects related to Inclusive Education in their programs. The absence of disciplines that addresses Inclusive Education in universities precludes a fundamental debate, especially in undergraduate courses, as the enrollment of students with disabilities in regular classes has been increasing significantly.

Keywords: Inclusive Education; Curriculum; Teacher training.

Resumen: El discurso que fundamenta la Educación Inclusiva pasa, entre otros aspectos, por una formación docente que sea capaz de considerar las diferencias de los estudiantes y su aprendizaje. En este sentido, es interesante entender hasta qué punto los currículos de los cursos de formación de docentes se han configurado para permitir debates y reflexiones sobre la diversidad de los estudiantes. Los datos aquí presentados son un recorte de la investigación doctoral titulada Formación de docentes y educación inclusiva: un análisis a la luz de la teoría crítica de la sociedad. Este artículo tuvo como objetivo identificar y caracterizar en el currículo de once cursos licenciatura en una universidad pública de Bahía, disciplinas relacionadas con el enfoque de la Educación Inclusiva. La investigación tiene un enfoque cualitativo y, por medio del análisis documental se analizaron los diagramas de flujo y los Proyectos Académicos Curriculares (PAC) de los cursos de formación docente. El análisis de contenido fue la metodología de análisis de datos elegida. El estudio evidenció que los cursos de Ciencias Biológicas, Educación Física, Historia y Pedagogía son los que ofrecen asignaturas obligatorias y/o opcionales relacionadas con la Educación Inclusiva en sus currículos. La ausencia de signaturas que aborden la educación inclusiva en las universidades impide un debate fundamental, especialmente en las licenciaturas, ya que el número de matrículas de estudiantes con discapacidades en clases regulares viene aumentando significativamente.

Palabras clave: Educación inclusiva; currículo; formación de docentes.

\section{Introdução}

O crescente movimento em torno da discussão sobre a Educação Inclusiva tem se destacado nos mais diversos setores sociais, influenciado por eventos e políticas internacionais. É possível presenciar, cada vez mais, a inserção da pessoa com deficiência e demais minorias em salas de aulas regulares, muito em função das orientações e políticas públicas adotadas no país, nas duas últimas décadas. No entanto, a presença de alunos com deficiência na escola, tem revelado questões que precisam ser problematizadas, como por exemplo, a ineficácia de um sistema escolar que sempre excluiu aqueles e aquelas que não se ajustavam aos padrões.

No atual cenário político e econômico brasileiro é urgente discutir uma forma de educação contrária à segregação e que tenha como meta a aprendizagem de todos. Os retrocessos e desconstruções, incertezas e inseguranças resultados das mudanças no novo cenário nacional exige uma educação que explore, mesmo considerando os limites sociais, outras formas de aprendizagem, possibilitando o contato e a experiência com o outro num movimento de reflexão aprofundada sobre a sociedade atual. Isso porque, as políticas públicas e os direitos sociais 
conquistados nas últimas décadas, vêm sofrendo relativa erosão em função das ofensivas conservadoras e ultraliberais da atual política brasileira.

Os problemas de aprendizagem não são exclusivos das pessoas com deficiência, visto os altos índices de evasão e repetência que, em última instância, são o reflexo de uma educação que precisa ser (re)pensada. A discussão da escolarização das pessoas com deficiência tem colaborado para desnudar os problemas da educação brasileira, que historicamente vem apresentando sinais de ineficiência.

Outra questão que pode enfraquecer a luta pela inclusão está relacionada às práticas de integração. O grande risco dessa proposta é que o sujeito se sente parte, quando de fato não é. Certo nível de integração, por exemplo, pela via do consumo, oferece uma sensação de pertencimento gerando um conformismo que é traduzido na impressão de que tudo funciona bem. Assim, a aquisição de bens de consumo já é suficiente para que as pessoas se sintam integradas a uma classe da qual nunca fizeram parte. Mesmo assim, defendem os interesses desta classe da qual não participam e que as oprime.

No que tange à educação das pessoas com deficiência, não é possível desconsiderar que a integração foi o primeiro movimento, que possibilitou o acesso destas pessoas às escolas regulares. No entanto, as críticas são feitas, já que os alunos com deficiência que passaram a frequentar a escola regular, experimentaram (e ainda continuam experimentando) situações discriminatórias e segregadoras. Isso se deu, principalmente, porque o aluno com deficiência era considerado responsável por seu insucesso, visto que as condições da escola não eram questionadas ou problematizadas.

Para Ainscow (2009), programas integrados já adotaram o caráter de aulas especiais dentro de escolas regulares. No entanto, o autor destaca que, apesar da inserção desses alunos, não houve mudança na organização escolar, seja em termos estruturais ou pedagógicos.

Mendes (2006, p.391) afirma que na integração, havia uma inserção parcial, ou seja, “[...] as pessoas com deficiência tinham o direito de conviver socialmente, mas que deveriam ser, antes de tudo, preparadas em função de suas peculiaridades para assumir papeis na sociedade". Em relação à inclusão, a autora destaca que ocorre uma mudança de perspectiva, na medida em que propõe todos os alunos, prioritariamente, na escola comum. Contudo, no Brasil, embora as perspectivas de mudança estejam incorporadas na legislação educacional, os sistemas não estão cumprindo com êxito as prerrogativas inerentes à proposta inclusivista (MENDES, 2006).

Considerando as contradições dos conceitos, é possível verificar que a definição de integração, apresenta muitos elementos que se aplicam perfeitamente ao conceito de educação inclusiva. Isso pode ser percebido pela utilização dos termos: individualização dos programas 
escolares, currículos adaptados, avaliações especiais, redução dos objetivos educacionais. Tal constatação tem o objetivo de chamar atenção para um falso entendimento, amplamente disseminado pelo governo e pelos documentos por ele produzidos, bem como pelos conteúdos divulgados nos cursos de formação inicial e continuada de professores, com o objetivo de sustentar uma ideia de uma temporalidade linear, responsável pela percepção de que a educação das pessoas com deficiência passou por fases, bem delimitadas, que podem ser assim resumidas: segregação, integração e inclusão. De acordo com esse entendimento, estaríamos vivendo a fase da inclusão.

Nesse sentido, a defesa pela escola inclusiva, não pode prescindir à crítica, capaz de reconhecer que práticas segregadoras continuam a existir, sobretudo, nas escolas regulares amparadas por discursos inclusivos. Assim, é urgente que as demandas sociais em prol da educação que considerem a segregação e a violência, expressas em práticas consideradas inclusivas, sejam (re)conhecidas, para que possam ser estudadas e enfrentadas. Se tais demandas remetem à formação dos indivíduos, não é menos verdadeiro que devam também ser consideradas pelos cursos de formação de professores, sobretudo porque estes profissionais têm um papel preponderante, no enfrentamento das diversas formas de violência manifestadas nas escolas. Não queremos com isso afirmar que esta é uma tarefa exclusiva dos professores, mas seria ingênuo não considerar que a formação dos professores é um dos principais desafios para a prática docente inclusiva (COSTA, 2015).

O foco do nosso estudo foi pensar a formação inicial dos docentes que atuam em classes regulares do Ensino Fundamental e Médio, visto que, de acordo com as notas estatísticas do Censo Escolar da Educação Básica (INEP, 2018), o percentual de alunos com deficiência, transtornos globais do desenvolvimento ou altas habilidades, incluídos em classe comum passou de 71,7\% em 2013, para 86,8\% em 2017. Os dados mais recentes indicam que entre os estudantes de 4 a 17 anos, público alvo da educação especial, é possível verificar um aumento no percentual de matrículas de alunos incluídos em classes comuns: no ano de 2019 esse número foi de 92,8\% (INEP, 2020). Considerando estes dados, é relevante analisar os aspectos que orientam a formação docente, visto que a atuação desse profissional é fundamental na constituição de práticas escolares inclusivas.

Diante do panorama apresentado até aqui, é crescente o número de pesquisas que revelam as lacunas na formação do professor e a relação desta formação com a inclusão de alunos com deficiência na escola regular (COSTA, 2013, 2015; CROCHÍK et al., 2011; MANTOAN, 2005; MENESES; PEDROSSIAN, 2013; MICHELS, 2005; SILVA, 2015; ROCHA-OLIVEIRA; DIAS; SIQUEIRA, 2019). Para Meneses e Pedrossian (2013), é fundamental romper com uma 
formação pautada na concepção de homogeneidade dos alunos, que tende a considerá-los como idênticos em seus variados aspectos.

Embora a necessidade formativa para a inclusão de alunos com deficiência seja comum aos docentes de todas as áreas, as pesquisas no campo da educação inclusiva têm se concentrado na formação de professores dos cursos de Pedagogia (FONSECA-JANES; OMOTE, 2013; JESUS; BARRETO; GONÇALVES, 2011; MARINHO, 2016; REZENDE, 2013; SOUZA, 2013). Contudo, com raras exceções, verificam-se lacunas na formação docente na maioria dos cursos de licenciatura, âmbito de atuação dos docentes das disciplinas específicas, demandando pesquisas que contribuam de forma mais ampla para mudanças no cenário educacional.

A partir do exposto e considerando o papel dos cursos de formação de professores para a efetivação de uma educação que considere a diversidade dos sujeitos, este artigo objetivou identificar e caracterizar no currículo de onze cursos de licenciatura de uma universidade pública baiana, disciplinas relacionadas à abordagem da Educação Inclusiva. A análise documental foi o procedimento metodológico utilizado e, o recorte feito neste artigo enfoca aspectos da estrutura curricular dos cursos pesquisados.

\section{Abordagem da deficiência nos currículos dos cursos de formação de professores}

De modo geral, os estudos que articulam currículo e educação inclusiva têm uma abordagem pautada em adaptações e flexibilizações curriculares. Para Carvalho (2010, p. 105), as adaptações curriculares estão relacionadas às "modificações espontaneamente realizadas pelos professores e, também, em todas as estratégias que são intencionalmente organizadas para dar respostas às necessidades de cada aluno, particularmente dos que apresentam NEEs ${ }^{1 "}$. A flexibilização do currículo é um conceito amplamente trabalhado nos documentos oficiais e de acordo com Garcia (2011) está relacionada a diversificação dos programas pedagógicos, da avaliação, entre outros.

Os fundamentos da Educação Inclusiva passam, entre outros aspectos, por uma formação docente capaz de considerar as diferenças dos alunos e suas aprendizagens. Neste sentido, é interessante entender em que medida os currículos dos cursos de formação de professores têm sido configurados para permitir discussões e reflexões sobre a diversidade dos alunos.

Entre o rol de políticas educacionais e que impactam as ações referentes à Educação Inclusiva, é resgatado um trecho da Resolução CNE/CP 02/15² (BRASIL, 2015) que define as

\footnotetext{
${ }^{1}$ Necessidades Educacionais Especiais.

2 A referida Resolução foi citada, pois era a Política vigente à época da pesquisa. A Resolução 2/2019 (BRASIL,2019) é a atual política que orienta a formação de professores e não apresentou avanços em relação à
} 
Diretrizes Curriculares Nacionais para a Formação Inicial em Nível Superior (cursos de licenciatura, cursos de formação pedagógica para graduandos e cursos de segunda licenciatura) e para a Formação Continuada:

Os cursos de formação deverão garantir nos currículos conteúdos específicos da respectiva área de conhecimento ou interdisciplinares, seus fundamentos e metodologias, bem como conteúdos relacionados aos fundamentos da educação, formação na área de políticas públicas e gestão da educação, seus fundamentos e metodologias, direitos humanos, diversidades étnico-racial, de gênero, sexual, religiosa, de faixa geracional, Língua Brasileira de Sinais (Libras), educação especial e direitos educacionais de adolescentes e jovens em cumprimento de medidas socioeducativas (BRASIL, 2015, p.11, grifo nosso).

Nessa perspectiva, interessa pensar como as universidades vêm elaborando seus currículos para formar profissionais aptos a atender à demanda do público da educação inclusiva, especialmente se considerarmos que esta formação é baseada em modelos e não em teorias. Nesse movimento, o currículo poderia ser um meio para que os professores, pudessem (re)pensar sua prática, problematizando, por exemplo, como a educação inclusiva pode proporcionar a identificação e o respeito com o outro.

Historicamente, a discussão sobre como trabalhar com a deficiência está pautada no chamado modelo médico-psicológico (MICHELS, 2005) ou modelo clínico-terapêutico (LOPES; FABRIS, 2013; SKLIAR, 2013). Skliar (2013, p. 8) considera, como modelo clínico terapêutico, "toda opinião e toda prática que anteponha valores e determinações acerca do tipo e nível da deficiência acima da ideia da construção do sujeito como pessoa integral, com sua deficiência específica”. Para Michels (2005), a concepção médico-psicológico privilegia a base biológica que, em última instância, explica o sucesso/insucesso do indivíduo. Independentemente da adjetivação, o modelo descrito por Skliar (2013) e Michels (2005) além de outros estudiosos que se debruçam a pesquisar esse modelo - evidencia os fatores biológicos que caracterizam a deficiência como determinante no processo de escolarização dos sujeitos com deficiência.

Em relação ao modelo acima descrito, pesquisas têm apontado sua predominância nos cursos de formação de professores. Talvez por isso, a maioria dos trabalhos que têm estudado a pessoa com deficiência nos processos educativos têm como pano de fundo tentar "corrigir" o déficit e aproximar esse aluno o máximo possível aos padrões de normalidade. Nesse processo, são desconsiderados fatores fundamentais, como, por exemplo, a heterogeneidade dos alunos

Educação Inclusiva. De acordo com o documento atual, as IES que já implementaram o previsto na Resolução 2/2015, terão o prazo limite de três anos, para adequação das competências previstas na atual Resolução. 
(independente do corpo que possuam) na compreensão dessa complexa trama, que faz parte do contexto educativo.

As críticas ao modelo médico-psicológico são evidenciadas nos trabalhos de alguns autores (FREITAS, 2013; LOPES; FABRIS, 2013; MICHELS, 2005; 2011; SILVA, 2006), que demonstram preocupações com a predominância desse modelo, embasando a formação dos profissionais que irão atuar com o público alvo da Educação Inclusiva.

Não se pode perder de vista que a intenção de incluir os alunos com deficiência na escola regular tem como objetivo a escolarização destes. Assim, o mínimo que se espera considerando as diferenças que são as marcas da individualidade dos sujeitos - é que sejam pensadas alternativas didático-pedagógicas que possibilitem a construção do conhecimento por parte de todos os alunos. Tomaremos como exemplo o processo de avaliação da aprendizagem, que é alvo de duras críticas no contexto escolar, visto que na maioria das vezes busca predominantemente os aspectos quantitativos em detrimento dos qualitativos. No contexto da educação inclusiva, esse cenário não é diferente, a implicação do simples ato de avaliar pode ser mais um elemento que exclui o aluno da escola regular. Nas palavras de Freitas (2013):

Ainda que qualquer aluno possa viver a experiência do insucesso nos processos de avaliação, os que são identificados com a inclusão muitas vezes têm no resultado um ponto de chegada e de finalização às expectativas de escolarização que seus familiares nutriram por um breve momento. (FREITAS, 2013, p. 55).

Se a própria deficiência é a responsável pelo fracasso escolar dos sujeitos atendidos pela Educação Inclusiva, a que/quem se deve atribuir o fracasso dos alunos sem deficiência excluídos socialmente e que experimentam cotidianamente esse fracasso? Nesse caso, a deficiência não é física, nem biológica. Enquanto a escola não reconhecer a sua incapacidade e que esse modelo pedagógico é excludente - não só para os alunos com deficiência, mas para negros, homossexuais, pobres, marginalizados, trabalhadores da periferia e pessoas que tenham dificuldade de aprender - as pessoas com deficiência continuarão experimentando situações de exclusão.

Em oposição ao modelo médico-psicológico, merece destaque o modelo social da deficiência. De acordo com Diniz (2012), este modelo surgiu a partir de estudos de pesquisadores com deficiência, tendo como um dos precursores o sociólogo Michel Oliver. As discussões sobre este modelo tiveram início na década de 1970, no Reino Unido com a criação da Union Physical Impairment Against Segregation (Upias), que foi a primeira organização política sobre a deficiência instituída e coordenada por deficientes. Autores como Diniz (2012), Piccolo e Mendes (2013a) defendem ser fundamental que as questões sociais sejam 
consideradas ao se discutir a deficiência, visto que não é só o sujeito com deficiência que precisa se adequar a esse modelo social, mas também o inverso.

Essa abordagem ganha força a partir da década de 80, no entanto, ainda é pouco explorada no Brasil. Piccolo e Mendes (2013b) investigaram as produções dos Programas de PósGraduação em Sociologia vinculados à CAPES, no período de 1990-2010, buscando identificar pesquisas cujo objeto de estudo fosse a deficiência. Foram investigados 5.691 trabalhos (entre teses e dissertações), dentre os quais apenas dez $(0,18 \%)$ abordavam a temática em questão. Para os autores este resultado "traça a sombria perspectiva do quanto a deficiência se compõe como um tema solenemente ignorado pelo campo" (PICCOLO; MENDES, 2013b, p. 465).

Os estudos antropológicos sobre a deficiência também denunciam questões basilares, que precisam ser problematizadas. Nesse sentido, Diniz e Santos (2010) apontam para uma questão fundamental, quando afirmam que, no caso da discriminação sofrida pelas pessoas com deficiência, sequer dispomos de categorias analíticas e discursivas que denunciem as formas de opressão sofridas por estas pessoas:

Para descrever essas formas perversas de opressão pelo corpo, dispomos de
categorias analíticas e discursivas: sexismo, no caso da discriminação por
sexo; homofobia, no caso da discriminação pela orientação sexual; racismo,
no caso da discriminação pela cor da pele ou etnia. No caso da deficiência, há
uma ausência no léxico ativo da língua portuguesa. Nossa incapacidade
discursiva é um indicador da invisibilidade social e política desse fenômeno.
Como descrever os resultados perversos da ideologia da normalidade sobre os
corpos com impedimentos? Como nominar as expressões da desigualdade
sofrida pelas pessoas com deficiência no mundo do trabalho, nas escolas e nas
relações interpessoais? (DINIZ; SANTOS, 2010, p. 10).

O modelo social da deficiência faz emergir outras possibilidades que podem permitir o questionamento e a ponderação sobre a estrutura social e o papel da escola nos processos de exclusão/inclusão a que são submetidos os sujeitos com e sem deficiência. Além disso, e, sobretudo por isso, tira do debate a velha e ultrapassada concepção que atribui ao corpo deficiente toda responsabilidade por seu fracasso e/ou não adaptação à sociedade.

\subsection{Educação Inclusiva, deficiência e currículo: produção de trabalhos no campo de formação de professores}

De modo geral, a discussão dos trabalhos que articulam currículo e educação inclusiva limita-se à abordagem das adaptações e flexibilizações curriculares, sem que haja uma análise crítica das causas que promovem a exclusão, das condições objetivas e psíquicas que constituem o preconceito, ou ainda reflexões sobre nossa sociedade. Diante da abordagem 
predominantemente trabalhada nos cursos de formação docente, é possível compreendermos as sucessivas críticas em relação à escolarização das pessoas com deficiência, já que tanto a escola quanto a universidade trabalham superficialmente, promovendo muitas vezes condições que limitam o acesso destas pessoas ao conhecimento.

Há um entendimento equivocado acerca das adaptações e flexibilizações curriculares, que normalmente são compreendidas apenas como meios para facilitar a aprendizagem. Talvez por isso, seja comum encontrarmos em salas de aulas crianças com deficiência pintando ou riscando um papel em branco, enquanto seus colegas aprendem operações matemáticas ou noções de gramática, por exemplo. Esse tipo de atitude, muitas vezes adjetivada de flexibilização ou adaptação curricular, tende a reforçar a segregação. Conforme afirma Crochík (2016, p. 49), “[...] deve-se adaptar ou adequar o método para o ensino, e o conteúdo a ser ministrado pode até ser um pouco menos complexo, mas não deve se dar atividades claramente diferenciadas das que são ofertadas ao resto da turma".

A falta de uma base teórica sólida para fundamentar os estudos sobre deficiência possibilita equívocos que interferem no processo de ensino e aprendizagem das pessoas com deficiência. Além disso, grande parte dos cursos de formação de professores, independente da área de conhecimento, não aborda as condições objetivas que obstam a educação voltada para a crítica dessas próprias condições, conduzindo a formação para a heteronomia; questões pedagógicas são trabalhadas de forma dissociada de outras questões fundamentais que afetam a escola e, portanto, interferem na construção do conhecimento. De forma geral, há quase uma tendência romantizada no trato das questões pedagógicas, que se acentua na educação das pessoas com deficiência.

No instante em que indagamos: "Educação - para quê?", onde este "para quê" não é mais compreensível por si mesmo, ingenuamente presente, tudo se torna inseguro e requer reflexões complicadas. E, sobretudo uma vez perdido este "para quê", ele não pode ser simplesmente restituído por um ato de vontade, erigindo um objetivo educacional a partir do seu exterior. (ADORNO, 1995a, p. 140).

A ausência de propósitos claros, dos elementos constituintes da educação tem conduzido a um cenário notável de esvaziamento teórico e também cultural em nossas escolas. Não será por meio de atos prescritivos, como afirma Adorno (1995a), que esse esvaziamento será reparado. Tampouco será por meio de decretos ou de modelos que primam o "aprender a aprender" que a crítica a esta forma de sociedade e, portanto, de escola, será possível. Se a Universidade não tem possibilitado esse debate nos cursos de formação de professores, 
justamente porque está submetida à racionalidade técnica, a reprodução desse modelo de currículo tende a se perpetuar.

Em relação ao currículo, falar de adaptações pode ser redundante: se existe um aluno que requer estratégias diferenciadas em sala de aula, não seria esperado que o professor, ou a escola, dispusesse de estratégias para esse aluno? Será que as adaptações e flexibilizações, da forma como vêm sendo trabalhadas, não estimulam a segregação? Embora estes recursos sejam importantes e necessários, cabe a reflexão sobre a excessiva ênfase nos meios, em substituição aos conteúdos, reduzindo estes em função daqueles. Em nome dos ajustes, o debate maior sobre o potencial do currículo para tratar das relações imbricadas entre escola e sociedade e as implicações destas no acesso ao conhecimento ficam secundarizadas.

A complexidade da questão entre currículo e relações de poder implica que educadores sejam levados a tomar consciência e a entender as conexões entre o que se passa na sala de aula (entre o que se ensina e as relações interpares ali estabelecidas) e o que é produzido fora da escola, isto é, com as relações de poder da sociedade que são mais amplas, desiguais e estruturais. Essa tomada de consciência por parte dos educadores é exigência de uma proposta de Educação que se oriente por criar as possibilidades de uma sociedade emancipada da opressão e da injustiça, tal como postulada por Theodor Adorno. (VILELA, 2007, p. 227).

Não se pode perder de vista que as práticas pedagógicas se configuram como ações do currículo. Nesse sentido, a relação entre currículo e educação inclusiva precisa ultrapassar a compreensão pautada na abordagem médica e, além disso, trazer à tona as questões que geram as desigualdades, a exclusão e o preconceito.

Com a intenção de verificar a relação entre currículo e educação inclusiva, pesquisamos trabalhos que articulassem os dois temas no Grupo de Trabalho sobre currículo (GT-12), publicados na Associação Nacional de Pós-Graduação e Pesquisa em Educação (ANPED), no período entre 2005 e 2015. É interessante notar que uma pesquisa realizada com o descritor 'educação inclusiva' não retornou qualquer resultado. Isso indica, de alguma maneira, que as discussões sobre currículo não abordaram, pelo menos como tema principal, a questão da inclusão na educação. A partir daí, resolvemos verificar individualmente todos os trabalhos publicados no período e constatamos, que de fato, há uma escassez de trabalhos neste GT que abordem a questão, mesmo num plano secundário. Usando o descritor 'diversidade', também não foram localizadas pesquisas sobre pessoas com deficiência. Entretanto, foram encontrados trabalhos sobre exclusão social de povos indígenas e o papel do currículo na construção da identidade negra, por exemplo. 
Ainda no âmbito dos trabalhos publicados na ANPED no mesmo período, verificamos, no GT-15 (Educação Especial), apenas dois em que o termo currículo aparece nomeando as produções, num total de 181 trabalhos. O trabalho Currículo e educação especial: uma relação de (re)invenção necessária a partir das imagens-narrativas dos cotidianos escolares (HAAS; BAPTISTA, 2015) investigou a articulação entre currículo e educação especial na produção acadêmica brasileira. De acordo com os autores, o estudo indicou a precariedade do debate acadêmico sobre o tema e destacou a relevância do investimento na compreensão do conceito de acessibilidade curricular. Já a pesquisa intitulada Currículo e diferença: processos de seleção e organização de conhecimentos para atendimento educacional de alunos com histórico de deficiência mental investigou alunos com deficiência intelectual matriculados em classes regulares e especiais. De acordo com as autoras, esses alunos acabam sendo excluídos, pois as práticas pedagógicas e os currículos impossibilitam os processos de elaboração conceitual, evidenciando negativamente suas capacidades. Afirmam ainda que "o problema fundamental está no fato de que nem o currículo, nem as práticas pedagógicas, nem o funcionamento da instituição escolar admitem, na atualidade, muita variação" (FERRI; HOSTINS, 2006, p. 15).

A pesquisa nos dois GTs, conforme apontado acima, indicou a escassez de produções que façam a articulação entre currículo e educação inclusiva. Os poucos trabalhos encontrados podem indicar a dificuldade da escola ao abordar temas relacionados à diferença, marcada pela condição de deficiência. Além disso, ficou nítida a compreensão limitada sobre adaptações curriculares ao evidenciar a dimensão técnica e instrumental dos currículos. Como afirmam Crochík et al. (2011, p. 569), "se as escolas não se modificam para atender os alunos que antes não as frequentavam ou então cursavam escolas especiais, e estabelecem métodos e currículos à parte unicamente para esses alunos, a segregação permanece".

Se, na escola, o currículo atua em favor da homogeneização, podemos entender esse aspecto como indicativo da abordagem que vem sendo dada ao tema nos cursos de formação de professores. Ainda que a escola apresente dinâmica e cultura próprias, ela acaba por influenciar e ser influenciada pelo conhecimento produzido na universidade. Assim, se a universidade compreende a escolarização das pessoas com deficiência pautada pelo viés da abordagem médica, se é incapaz de articular uma discussão que problematize os fatores responsáveis pela desigualdade, ou ainda, que não seja capaz de pensar o currículo como mecanismo de dominação, é esperado que ele ainda atue na exclusão das minorias. 


\section{Percurso metodológico}

Nesta pesquisa, a abordagem qualitativa de cunho empírico é a que apresenta os melhores requisitos para a compreensão do objeto. De acordo com Horkheimer e Adorno (1973, p. 125), “[...] já se reconhece a necessidade de uma análise qualitativa, não só como integração, mas também como elemento constitutivo da investigação social empírica".

O estudo foi realizado em uma universidade pública no estado da Bahia, que tem grande tradição na formação de professores das diversas áreas de conhecimento. Foram investigados os currículos de onze cursos de licenciatura, modalidade presencial, das seguintes áreas de conhecimento: Ciências Exatas, Ciências Biológicas, Ciências Humanas e Linguagens.

A análise documental foi o procedimento metodológico utilizado para identificar nos fluxogramas dos cursos pesquisados, disciplinas relacionadas à abordagem da Educação Inclusiva. Este processo envolveu duas fases:

a) Inicialmente foram analisados os títulos de todas as disciplinas obrigatórias nos fluxogramas de cada um dos onze cursos pesquisados, disponibilizados no site da instituição, o que totalizou $494^{3}$ títulos. Destes, foram selecionadas as disciplinas que continham os descritores inclusiva, inclusão, especial, deficiência, deficiente, adaptação/adaptado e atendimento. A identificação dos cursos que ofertavam a disciplina de Libras também foi realizada nesta etapa.

b) A análise dos fluxogramas permitiu a identificação apenas das disciplinas obrigatórias presentes nos currículos dos cursos. Nesse sentido, foi necessário examinarmos os Projetos Acadêmicos Curriculares (PACs), para localizarmos, a partir dos mesmos descritores citados anteriormente, as disciplinas optativas de cada curso de licenciatura, relacionadas à educação inclusiva.

\section{Análise e discussão dos dados}

A análise de dados seguiu a linha da análise de conteúdo. De acordo com Adorno (2008), este método foi desenvolvido por Lasswell na década de 1930 e, embora tenha características essencialmente quantitativas, também prevê momentos qualitativos: "não é possível quantificar nada que não tenhamos antes determinado também qualitativamente. Penso que este é um princípio de todo problema metodológico da sociologia acerca do qual é preciso ter clareza"

\footnotetext{
${ }^{3} \mathrm{O}$ total de disciplinas encontradas nos fluxogramas diverge daqueles apresentados na tese, pois após a sua publicação, os cursos de Licenciatura em Educação Física e História da universidade pesquisada fizeram alterações em seus Programas Acadêmico Curriculares, alterando assim o número de disciplinas.
} 
(ADORNO, 2008, p. 219). Reafirmamos que a abordagem qualitativa de cunho empírico é a que apresenta os melhores requisitos para a compreensão do objeto dessa pesquisa.

\subsection{Identificação das disciplinas que contemplam a Educação Inclusiva e/ou Educação Especial em seus títulos}

Ao efetuar a busca pelas disciplinas obrigatórias e/ou optativas que contemplassem em seus títulos os descritores inclusiva, inclusão, especial, deficiência, deficiente, adaptação/adaptado e atendimento, foi possível verificar que, dos onze cursos de licenciatura investigados, quatro apresentam em seus currículos disciplinas que atenderam ao critério da busca. Em termos percentuais, esse total equivale a 36,4\% dos cursos pesquisados.

Das 493 disciplinas obrigatórias analisadas, apenas nove atenderam os critérios da pesquisa, o que corresponde a um percentual de 1,8\% de disciplinas que abordam a educação inclusiva nos currículos dos cursos pesquisados.

Esse número é bastante inexpressivo diante da importância que este tema representa na formação de professores. Se considerarmos que o curso de licenciatura em Ciências Biológicas só possui disciplinas optativas relacionadas à temática, esse número pode sofrer variação, pois na condição de optativa, não há garantias de que os alunos cursem as referidas disciplinas. Estes dados podem ser verificados no Quadro 1.

Quadro 1: Disciplinas obrigatórias e optativas encontradas nos cursos de licenciaturas pesquisados ${ }^{4}$.

\begin{tabular}{|c|c|c|c|}
\hline $\begin{array}{l}\text { Curso de } \\
\text { licenciatura }\end{array}$ & Disciplina (s) & $\begin{array}{l}\text { Natureza da } \\
\text { disciplina }\end{array}$ & $\begin{array}{c}\text { Carga } \\
\text { Horária }\end{array}$ \\
\hline & Educação Inclusiva & Optativa & 60 horas \\
\hline Ciências Biológicas & $\begin{array}{l}\text { Educação Inclusiva para o Ensino de Ciências e } \\
\text { Biologia }\end{array}$ & Optativa & 60 horas \\
\hline \multirow{4}{*}{ Educação Física } & $\begin{array}{l}\text { Met. de Ensino de Atividade Física } \\
\text { Adaptada } \\
\end{array}$ & Obrigatória & 45 horas \\
\hline & $\begin{array}{l}\text { Oficinas Pedagógicas VI: } \\
\text { Educação Inclusiva }\end{array}$ & Obrigatória & 60 horas \\
\hline & $\begin{array}{l}\text { Metodologia de Ensino da } \\
\text { Educação Física Inclusiva }\end{array}$ & Obrigatória & 45 horas \\
\hline & Esporte Adaptado & Optativa & 45 horas \\
\hline História & $\begin{array}{l}\text { Seminário Temático: Educação } \\
\text { Inclusiva }\end{array}$ & Obrigatória & 45 horas \\
\hline \multirow[b]{2}{*}{ Pedagogia } & Educação Especial e Inclusiva & Obrigatória & 60 horas \\
\hline & $\begin{array}{l}\text { Atendimento Educacional a pessoas } \\
\text { com deficiência }\end{array}$ & Optativa & 45 horas \\
\hline
\end{tabular}

Fonte: Dados da pesquisa, 2020.

${ }^{4}$ Os dados referentes as disciplinas dos cursos de Educação Física e História foram atualizados, visto que houve alteração nas disciplinas ofertadas por estes cursos desde a publicação dos dados da tese, em 2018, que serviram de referência para este artigo. 
Importante ressaltar que os cursos de Educação Física e História, recentemente, realizaram alterações em seus currículos. Esta informação é relevante na medida em que, tais alterações passaram a contemplar disciplinas acerca da Educação Inclusiva em seus currículos. Em 2018, quando os dados da pesquisa de doutorado, que serviram de base para a escrita desse artigo foram publicados, o curso de História não apresentava em seu currículo nenhuma disciplina relacionada a temática. Atualmente apresenta uma disciplina obrigatória, aspecto que consideramos de extrema relevância para o debate sobre a escolarização das pessoas com deficiência na formação de futuros professores.

Já o curso de Educação Física que apresentava uma disciplina obrigatória no currículo antigo, atualmente conta com três disciplinas obrigatórias e uma optativa, como é possível verificar no quadro 1. Além da quantidade de disciplinas, outro avanço verificado no currículo, diz respeito às suas nomenclaturas. No currículo antigo, a disciplina que tratava da educação inclusiva era intitulada Educação Física Especial. No atual, o termo especial não aparece nomeando nenhuma disciplina. Consideramos um avanço a troca do termo especial pelo termo inclusiva, identificado nas disciplinas do curso de Educação Física. Já a disciplina do curso de Pedagogia contém os dois vocábulos: especial e inclusiva.

Consideramos que o especial da educação especial, tende a demarcar um lugar destinado ao diferente, o que pode indicar segregação. Nesse sentido, a presença desse termo nomeando as disciplinas pode indicar o entendimento dos cursos a respeito da compreensão acerca da escolarização das pessoas com deficiência. No entanto, não podemos desconhecer que estes cursos estão amparados pela própria legislação, já que a educação especial, desde a LDB (BRASIL, 1996), e ainda hoje com as Diretrizes Curriculares Nacionais para a formação inicial em nível superior e para a formação continuada é considerada uma modalidade da educação (BRASIL, 2015).

Outro aspecto observado a partir dos dados do quadro 1, diz respeito à baixa carga horária das disciplinas relacionas à Educação Inclusiva, em relação a carga horária total dos cursos. Se considerarmos que, a Resolução no 2/2015 (BRASIL, 2015, p. 16) afirma que os cursos de licenciatura "terão no mínimo 3.200 horas de efetivo trabalho acadêmico", reconhecemos que a carga horária disponibilizada para estas disciplinas, de 45 a 60 horas, é reduzida. Resultados semelhantes foram encontrados nas pesquisas de Fonseca-Janes; Omote (2013), Oliveira (2013), Simões (2016), Vitaliano (2007).

Em relação ao número de cursos que ofertam componentes curriculares relacionados à educação das pessoas com deficiência, nossos dados se aproximam do estudo de Simões (2016), que investigou quinze cursos de licenciatura de distintas áreas do conhecimento, em 27 
universidades federais brasileiras. A autora é enfática ao afirmar que "a educação das pessoas com deficiência não parece ser alvo prioritário de preocupação nas licenciaturas das universidades brasileiras" (SIMÕES, 2016, p. 126).

Em recente estudo, Borges, Santos e Costa (2019) investigaram como os cursos de Licenciatura da Universidade Federal de Goiás - Regional Catalão (RC-UFG), têm ofertado disciplinas e temáticas relacionadas à educação especial. Para as autoras:

[...] são evidentes os avanços na formação inicial de professores da RC/UFG, mas, ao considerarmos que apenas cinco dos 12 cursos investigados apresentam disciplinas e/ou inserção de conteúdos, além da específica da surdez com a oferta da Libras, podemos inferir que há muito o que avançar para conseguirem responder às demandas de inclusão escolar na educação básica. (BORGES; SANTOS; COSTA, 2019, p. 153).

Nossa pesquisa revelou, ainda, que a prevalência da discussão da temática ocorre prioritariamente no curso de Educação Física, com três disciplinas obrigatórias e uma optativa, seguido do curso de Pedagogia, com duas disciplinas (uma obrigatória e outra optativa). Consideramos esse resultado extremamente relevante, pois sinaliza a responsabilidade de outros cursos de licenciatura, que não apenas os de Pedagogia, reconhecerem a abordagem da temática, nos cursos de formação de professores. Resultados semelhantes foram encontrados no estudo de Borges, Santos e Costa (2019, p. 153). Para as referidas autoras, não é possível "[...] desconsiderar os avanços dos cursos investigados, principalmente os cursos de Educação Física e Pedagogia, que têm contemplado essa temática no ensino, pesquisa, estágios e grupos de estudos".

Ainda que a nossa pesquisa evidencie que o curso de Educação Física apresenta o maior número de disciplinas relacionadas à temática da inclusão, outros estudos têm apontado que, tradicionalmente, o curso de Pedagogia é o que apresenta um maior número de disciplinas relacionadas à Educação Inclusiva (DIAS, 2018; JESUS; BARRETO; GONÇALVES, 2011; MICHELS, 2005; PIMENTEL, 2012; SOUZA, 2013; PRAIS; ROSA, 2017).

De acordo com Jesus, Barreto e Gonçalves (2011, p.89), o fato de os cursos de Pedagogia, tradicionalmente, apresentarem o maior número de disciplinas relacionados a Educação Inclusiva pode “continuar 'fortalecendo o imaginário' de que os alunos da modalidade Educação Especial continuarão cursando somente os níveis de Educação Infantil e os anos iniciais do Ensino Fundamental e que são os formandos em Pedagogia aqueles a se 'formarem' para tal”. Todavia, os princípios de uma educação pautada no respeito às diferenças, podem ser trabalhados desde a educação infantil. Em Educação e Emancipação, Adorno (1995b) destaca como a educação na primeira infância é decisiva para a formação. Para o autor: 
A educação tem sentido unicamente como educação dirigida a uma autorreflexão crítica. Contudo, na medida em que, conforme os ensinamentos da psicologia profunda, todo caráter, inclusive daqueles que mais tarde praticam crimes, forma-se na primeira infância, a educação que tem por objetivo evitar a repetição precisa se concentrar na primeira infância. (ADORNO, 1995b, p. 121-122).

Ademais, o curso de licenciatura em Ciências Biológicas, só apresentou disciplinas optativas referentes a abordagem da temática. A questão a ser observada é que na condição de optativas não há garantias de que sejam ofertadas, já que dependem diretamente do interesse particular dos licenciandos, bem como da disponibilidade dos docentes em ofertá-las regularmente. O estudo recente de Rocha-Oliveira, Dias e Siqueira (2019) também investigou o currículo de um curso de licenciatura em Biologia, acerca da abordagem da educação inclusiva. De acordo com os autores, não foram identificados indícios de que o referido curso promova uma formação docente que considere a inclusão de alunos com deficiências na educação básica (ROCHA-OLIVEIRA; DIAS; SIQUEIRA, 2019).

Um aspecto que merece ser destacado diz respeito a um discurso que costuma ser veiculado, sobretudo na academia, de que a simples presença de uma disciplina não possibilita a discussão necessária sobre a educação inclusiva. De fato, os mecanismos que envolvem a formação do preconceito ou o debate sobre as condições objetivas que causam segregação, aspectos imprescindíveis no debate sobre inclusão, possivelmente não se esgotam na abordagem de uma disciplina. Contudo, não é possível desconsiderar que ter um espaço para discutir e pensar uma questão tão urgente, especialmente se estamos considerando um espaço de formação de professores, não é uma questão menor; uma instituição com a responsabilidade social que tem a universidade, não pode se omitir diante de tal fato.

\subsection{As disciplinas de Libras}

A presença da disciplina Língua Brasileira de Sinais (Libras) foi identificada em todos os cursos pesquisados. Este fato deve estar associado à obrigatoriedade da oferta da referida disciplina nos cursos de licenciatura do país, conforme a Lei 10.436/2002 (BRASIL, 2002) e Decreto 5.626/2005 (BRASIL, 2005). Nesse sentido, este resultado indica o atendimento da legislação vigente.

Em todas as licenciaturas, a carga horária destinada à disciplina corresponde a 60 horas. $\mathrm{Na}$ instituição pesquisada, a disciplina está lotada no Departamento de Letras e Artes. Há variações nas ementas, embora seja possível verificar uma mesma ementa sendo utilizada por cursos distintos, como nos casos dos cursos de Letras e História. É perceptível que os cursos 
fizeram ajustes, conforme necessidades especificas, considerando que não há uma diretriz curricular nacional que norteie o ensino da Libras. Abaixo, a descrição de algumas ementas:

Aquisição da língua de sinais. Estrutura Linguística e as regras gramaticais de Libras. Libras e o fazer pedagógico. (Lic. em Geografia, grifo nosso).

O cérebro e a língua de sinais. Processos cognitivos e linguísticos. Tópicos de linguística aplicados à língua de sinais: morfossintaxe. Uso de expressões faciais gramaticais e afetivas. O processo de aquisição da leitura e escrita da língua de sinais. O alfabetismo na escrita da língua de sinais. (Lic. em Letras e Lic. em História, grifo nosso).

Apresenta a estrutura da língua de sinais nos níveis fonológicos e morfossintáticos. Proporciona a aquisição prática da língua de sinais em situações de comunicação bilíngue, reconhecendo o direito do surdo de ser aprendiz da Língua Brasileira de Sinais - LIBRAS enquanto língua natural. (Lic. em Pedagogia, grifo nosso).

A estrutura linguística e as regras gramaticais da LIBRAS; LIBRAS e o fazer pedagógico; noções básicas conceituais e práticas de LIBRAS. (Lic. em Química e Lic. Em Educação Física, grifo nosso).

Interessante notar que nas ementas supracitadas, nada é mencionado sobre inclusão. A análise indica que as disciplinas abordam predominantemente os processos linguísticos e aspectos práticos da Libras. Resultado divergente foi encontrado no estudo de Vitaliano, Dall'Acqua e Brochado (2013) quando investigaram currículos dos cursos de Pedagogia de universidades públicas dos estados de São Paulo e Paraná. Os resultados apontaram que a maioria dos cursos "prevê objetivos e conteúdos voltados para conhecimento da cultura surda, o processo educacional dos alunos surdos e aspectos linguísticos da Libras" (VITALIANO; DALL'ACQUA; BROCHADO, 2013, p. 115).

Concordamos com Cruz e Glat (2014) quando afirmam que a disciplina Libras pode representar uma importante ferramenta para a comunicação dos futuros professores com os alunos surdos, embora ela tenha figurado muito mais como uma forma de atender a legislação vigente.

Simões (2016) investigou cursos de licenciaturas de vinte e sete universidades federais de todas as regiões brasileiras. Em relação às disciplinas de Libras analisadas, a autora afirma:

[...] considera-se que é possível que o ensino de Libras esteja sendo realizado de forma incipiente e que também as leis e as regulamentações, impostas aos cursos, não tenham alcançado o nível de objetividade para imprimir certa coerência aos objetivos da inclusão dessa disciplina no currículo de formação de professores. (SIMÕES, 2016, p. 83). 
A presença da disciplina Libras nos currículos de todos os cursos pesquisados revela a força da legislação no que diz respeito ao atendimento de suas determinações, embora isso não signifique a presença de um debate crítico que colabore com a formação dos licenciandos. Sobre isso, Costa e Leme (2016, p.33) advertem que "[...] é preciso considerar que Leis, Convenções, Declarações e os Decretos podem oferecer aportes e subsídios; mas a consciência crítica somente será possível se constituir nos espaços de formação oportunizados aos professores".

\section{Considerações Finais}

Este estudo teve como objetivo identificar e caracterizar no currículo de onze cursos de licenciatura de uma universidade pública baiana, disciplinas relacionadas a abordagem da Educação Inclusiva.

A pesquisa revelou que os cursos de licenciatura em Ciências Biológicas, Educação Física, História e Pedagogia têm disciplinas (obrigatórias e/ou optativas) relacionadas à Educação Inclusiva em seus currículos. Nesse sentido, merece destaque o curso de Educação Física que oferta três disciplinas obrigatórias e uma optativa relacionada a temática investigada, revelando, portanto, o alinhamento do referido curso, com o debate da Educação Inclusiva.

Em todos os currículos analisados foi possível perceber a presença da disciplina de Libras, muito embora suas ementas não apontem para a abordagem da inclusão, o que indica que está presente, predominantemente, como forma de atender à legislação vigente.

A ausência de disciplinas que abordem a educação inclusiva nas universidades impossibilita um debate fundamental, sobretudo nas licenciaturas, visto que o número de matrículas de alunos com deficiência nas classes regulares vem crescendo significativamente. Assim, tal ausência reforça, além dos mecanismos de exclusão, a justificativa de que os professores não são formados para atuar na educação das pessoas com deficiência.

Considerando que as universidades gozam de um reconhecido papel social, possuem autonomia perante outras instituições e, têm função imprescindível na formação de professores, é fundamental que esteja alinhada com a proposta inclusiva de educação. Nesse sentido, os currículos dos cursos de licenciatura têm papel relevante na proposição de uma educação contrária a quaisquer formas de exclusão. 


\section{REFERÊNCIAS}

ADORNO, Theodor Wiesengrund. Educação - para quê? In: ADORNO, Theodor Wiesengrund. Educação e emancipação. Tradução Wolfgang Leo Maar. Rio de Janeiro: Paz e Terra, 1995a.

ADORNO, Theodor Wiesengrund. Educação após Auschwitz. In: ADORNO, Theodor Wiesengrund. Educação e emancipação. Tradução Wolfgang Leo Maar. Rio de Janeiro: Paz e Terra, $1995 b$.

ADORNO, Theodor Wiesengrund. Introdução à Sociologia. Tradução Wolfgang Leo Maar. São Paulo: Editora UNESP, 2008.

AINSCOW, Mel. Tornar a educação inclusiva: como esta tarefa deve ser conceituada? In: FÁVERO, Osmar. (Org.). Tornar a educação inclusiva. Brasília: UNESCO, 2009.

BORGES, Wanessa Ferreira; SANTOS, Cristiane da Silva; COSTA, Maria da Piedade Resende da. Educação Especial e formação de professores: uma análise dos projetos pedagógicos de curso (PPC). Revista Ibero-Americana de Estudos em Educação, Araraquara, v. 14, n. 1, p. 138-156, jan./mar., 2019. Disponível em: https://periodicos.fclar.unesp.br/iberoamericana/article/view/11267/7883 Acesso em: 13 abr.2020.

BRASIL. Lei no 9.394, de 20 de dezembro de 1996. Estabelece as diretrizes e bases da educação nacional. Brasília, DF, 1996. Disponível em:

<http://www.planalto.gov.br/ccivil_03/leis/19394. htm>. Acesso em: 04 abril 2016.

BRASIL. Lei 10.436 de 2002. Dispõe sobre a Língua Brasileira de Sinais - Libras e dá outras providências. Diário Oficial da República Federativa do Brasil, Brasília, 2002. Disponível em: <http://www.planalto.gov.br/ccivil_03/leis/2002/110436.htm>. Acesso em: 05 abr. 2015.

BRASIL. Decreto n. 5.626. Regulamenta a Lei n. 10.436, de 24 de abril de 2002. Dispõe sobre a Língua Brasileira de Sinais - LIBRAS. Diário Oficial da República Federativa do Brasil, Brasília, 2005. Disponível em: <http://www.planalto.gov.br/ccivil_03/_ato20042006/2005/decreto/d5626.htm>. Acesso em: 05 abr. 2015.

BRASIL. Resolução n⿳ 2, de $\mathbf{1}^{\mathbf{0}}$ de julho de 2015. Define as Diretrizes Curriculares Nacionais para a formação inicial em nível superior (cursos de licenciatura, cursos de formação pedagógica para graduados e cursos de segunda licenciatura) e para a formação continuada. Brasília, Diário Oficial [da] República Federativa do Brasil, seção 1, n. 124, p. 8 12, 02 de julho de 2015. Disponível em:

$<$ http://portal.mec.gov.br/index.php?option=com_docman\&view=download\&alias=17719res-cne-cp-002-03072015\&Itemid=30192 > . Acesso em: 07 fev. 2017.

BRASIL. Resolução no 2, de 20 de dezembro de 2019. Define as Diretrizes Curriculares Nacionais para a Formação Inicial de Professores para a Educação Básica e institui a Base Nacional Comum para a Formação Inicial de Professores da Educação Básica. Brasília, DF, dezembro, 2019. Disponível em: https://abmes.org.br/arquivos/legislacoes/Resolucao-CNECEB-002-2019-12-20.pdf. Acesso em: 27 abr. 2020. 
COSTA, Valdelúcia Alves da. Experiências pela Educação - Para quê? Formação e Inclusão na perspectiva da Teoria Crítica. Revista Educação Especial. Santa Maria v. 26, n. 46, p. 245-260, maio/ago. 2013. Disponível em:

<https://periodicos.ufsm.br/index.php/educacaoespecial/article/view/8029/pdf. >. Acesso em: 08 fev. 2014.

COSTA, Valdelúcia Alves da. As demandas da formação e da prática docente inclusiva sob a égide dos direitos humanos. In: SILVA, Aída Maria Monteiro; COSTA, Valdelúcia Alves da (Orgs.). Educação inclusiva e direitos humanos: perspectivas contemporâneas. São Paulo: Cortez, 2015.

COSTA, Valdelúcia Alves da; LEME, Erika. Educação inclusiva no Brasil: aspectos políticos, sociais e humanos. In: COSTA, Valdelúcia Alves da (Org.). Educação inclusiva na América Latina: políticas, pesquisas e experiências. Niterói: Intertexto, 2016.

CROCHÍK, José Leon. Dados censitários e de pesquisas sobre Educação Inclusiva no Brasil. In: COSTA, Valdelúcia Alves da (Orgs.). Educação inclusiva na América Latina: políticas, pesquisas e experiências. Niterói: Intertexto, 2016.

CROCHÍK, José Leon et al. Análise de atitudes de professoras do ensino fundamental no que se refere à educação inclusiva. Educação e Pesquisa, São Paulo, v.37, n.3, p. 565 -582, set./dez. 2011. Disponível em: <http://www.scielo.br/pdf/ep/v37n3/a08v37n3.pdf>. Acesso em: 02 out. 2013.

CRUZ, Gilmar de Carvalho; GLAT, Rosana. Educação inclusiva: desafio, descuido e responsabilidade de cursos de licenciatura. Educar em Revista, Curitiba, Brasil, n. 52, p. 257 273, abr./jun. 2014. Disponível em: http://www.scielo.br/pdf/er/n52/15.pdf. Acesso em: 11 abr. 2019.

DIAS, Viviane Borges. Formação de professores e educação inclusiva: uma análise à luz da teoria crítica da sociedade. 2018. 263 f. Tese (Doutorado em Educação). Programa de PósGraduação em Educação e Contemporaneidade (PPGEduC) da Universidade do Estado da Bahia (UNEB), Salvador, 2018.

DINIZ, Débora. O que é deficiência. São Paulo: Brasiliense, 2012.

DINIZ, Débora; SANTOS, Wederson Rufino dos. Deficiência e direitos humanos: desafios e repostas à discriminação. In: DINIZ, D.; SANTOS, Wederson Rufino dos (Orgs.).

Deficiência e discriminação. Brasília: LetrasLivres: EdUnB, 2010.

FERRI, Cássia; HOSTINS, Regina Célia Linhares. Currículo e diferença: processos de seleção e organização de conhecimentos para atendimento educacional de alunos com histórico de deficiência mental. 29a Reunião Anual da ANPED, Caxambu - MG, 2006. Disponível em: <http://29reuniao.anped.org.br/trabalhos/trabalho/GT15-2605--Int.pdf>. Acesso em: 05 maio 2017.

FONSECA-JANES, Cristiane Regina Xavier; OMOTE, Sadao. Os Cursos de Pedagogia da Universidade Estadual Paulista e a Educação Inclusiva1. Rev. Bras. Ed. Esp., Marília, v. 19, n. 3, p. 325-342, Jul.-Set., 2013. Disponível em:<http://www.scielo.br/pdf/rbee/v19n3/03.pdf>. Acesso em: 05 abr. 2017. 
FREITAS, Marcos Cézar de. O aluno incluído na educação básica: avaliação e permanência. São Paulo: Cortês, 2013.

HAAS, Clarissa; BAPTISTA, Cláudio Roberto. Currículo e educação especial: uma relação de (re)invenção necessária a partir das imagens-narrativas dos cotidianos escolares. In:

Reunião Anual da Associação Nacional de Pós-Graduação E Pesquisa Em Educação, 37ª ., 2015, Florianópolis. Anais eletrônicos... UFSC - Florianópolis. Disponível em: <http://www.anped.org.br/sites/default/files/trabalho-gt15-4199.pdf >. Acesso em: 04 maio 2017.

HORKHEIMER, Max; ADORNO, Theodor Wiesengrund. Sociologia e investigação social empírica. In: HORKHEIMER, Max; ADORNO, Theodor Wiesengrund Temas básicos da Sociologia. Trad. Álvaro Cabral. São Paulo: Editora Cultrix - Editora da Universidade de São Paulo, 1973.

INEP. Instituto Nacional de Estudos e Pesquisas Educacionais Anísio Teixeira. Censo Escolar da Educação Básica 2017 - Notas estatísticas. Ministério da Educação. Brasília, DF. 2018. Disponível em: <https://drive.google.com/file/d/1ul8OptGdTzory5J0mTvvSzILCrXmWeE/view>. Acesso em: 02 fev. 2018.

INEP. Instituto Nacional de Estudos e Pesquisas Educacionais Anísio Teixeira. Censo Escolar da Educação Básica 2019 - Notas estatísticas. Ministério da Educação. Brasília, DF. 2020. Disponível em: http://portal.inep.gov.br/informacao-da-publicacao/-

/asset_publisher/6JYIsGMAMkW1/document/id/6798882. Acesso em: 06 abr. 2020.

JESUS, Denise Meyrelles de; BARRETO, Maria Aparecida Santos Correa; GONÇALVES, Agda Felipe da Silva. A formação do professor olhada no/pelo GT-15 - Educação Especial da ANPED: desvelando pistas. Rev. Bras. Ed. Esp., Marília, v.17, p.77-92, Mai-Ago., 2011. Edição Especial. Disponível em: 〈http://www.scielo.br/pdf/rbee/v17nspe1/07.pdf>. Acesso em: 26 maio 2016.

GARCIA, Rosalba Maria Cardoso. O conceito de flexibilidade curricular nas políticas de inclusão educacional. In: JESUS, Denise Meyrelles de, et al. (Orgs.). Inclusão, práticas pedagógicas e trajetórias de pesquisa. Porto Alegre: Mediação, 2011.

LOPES, Maura Corcini; FABRIS, Eli Henn. Inclusão \& Educação. Belo Horizonte: Autêntica Editora, 2013.

MANTOAN, Maria Tereza Eglér. A hora da virada. Inclusão: revista de Educação Especial, Brasília, DF, v. 1, n. 1, p. 24-28, 2005. Disponível em: <http://portal.mec.gov.br/seesp/arquivos/pdf/revistainclusao1.pdf〉. Acesso em: 12 mar. 2017.

MARINHO, Carla Cristina. Concepções de estudantes de pedagogia sobre educação inclusiva e educação especial e suas atitudes sociais em relação à inclusão. (Dissertação de Mestrado). Universidade Estadual Paulista: Marília, 2016. Disponível em:

<https://repositorio.unesp.br/bitstream/handle/11449/144631/marinho_cc_me_mar.pdf?seque nce=3\&isAllowed=y>. Acesso em: 05 abr. 2017. 
MENDES, Enicéia Gonçalves. A radicalização do debate sobre inclusão escolar no Brasil. Revista Brasileira de Educação, v.11, n.33, p. 387-405, 2006. Disponível em: <https://www.scielo.br/pdf/rbedu/v11n33/a02v1133.pdf>. Acesso em: 20 jul. 2017.

MENESES, Branca Maria; PEDROSSIAN, Dulce Regina dos Santos. A ideologia da integração na educação inclusiva. In: SILVA, L.M. da; SOUZA, L.R. (Orgs.). Estudos sobre formação e educação inclusiva. Salvador: EDUNEB, 2013.

MICHELS, Maria Helena. Paradoxos da formação de professores para a educação especial: o currículo como expressão da reiteração do modelo médico-psicológico. Rev. Bras. Educação Especial. Marília, Mai.-Ago. 2005, v.11, n.2, p.255-272. Disponível em: <http://www.scielo.br/pdf/rbee/v11n2/v11n2a7.pdf>. Acesso em: 20 jul. 2015.

MICHELS, Maria Helena. O que há de novo na formação de professores para a Educação Especial? Rev. Educ. Espec., Santa Maria, v. 24, n. 40, p. 219-232, maio/ago. 2011. Disponível em: <http://www.ufsm.br/revistaeducacaoespecial〉. Acesso em 01 fev. 2014.

OLIVEIRA, Clarissa da Silva. Decorrências do processo formativo com vistas à educação inclusiva no fazer pedagógico de egressos dos cursos de licenciatura da UFSM.

Dissertação (mestrado). Universidade Federal de Santa Maria. Programa de Pós Graduação em Educação, RS, 2013. Disponível em:

$<$ http://repositorio.ufsm.br/bitstream/handle/1/7055/OLIVEIRA\%2c\%20CLA

RISSA\%20DA\%20SILVA.pdf?sequence=1\&isAllowed=y> Acesso em: 05 fev. 2018.

PICCOLO, Gustavo Martins; MENDES, Enicéia Gonçalves. Sobre formas e conteúdos: a deficiência como produção histórica. Perspectiva, Florianópolis, v. 31, n. 1, 283-315, jan./abr. 2013a. Disponível em:

https://periodicos.ufsc.br/index.php/perspectiva/article/view/2175-

795X.2013v31n1p283/25658 . Acesso em: 17 abr. 2016.

PICCOLO, Gustavo Martins; MENDES, Enicéia Gonçalves. Contribuições a um pensar sociológico sobre a deficiência. Educação \& Sociedade. Campinas, v.34, n.123, p. 459-475, abr-jun.2013b. Disponível em: <http://www.scielo.br/pdf/es/v34n123/08.pdf.> Acesso em: 13 maio 2015.

PIMENTEL, Susana Couto. Formação de professores para a inclusão: saberes necessários e percursos formativos. In: MIRANDA, Terezinha Guimarães; GALVÃO FILHO, Teófilo (Orgs.). O professor e a educação inclusiva: formação, práticas e lugares. Salvador: EDUFBA, 2012.

PRAIS, Jacqueline Lidiane de Souza; ROSA, Vanderlei Flor da. A formação de professores para inclusão tratada na Revista Brasileira de Educação Especial: uma análise. Revista Educação Especial, v. 30, n. 57, p. 129-144, jan./abr. 2017. Disponível em: https://periodicos.ufsm.br/educacaoespecial/article/view/19833/pdf Acesso em: 13 abr. 2020.

REZENDE, Evelin Oliveira de. Formação de professores e a interveniência das diretrizes curriculares nacionais da Pedagogia para a Educação Especial. Dissertação de Mestrado, UFSCar, São Carlos, SP, 2013. Disponível em: 
$<$ https://repositorio.ufscar.br/bitstream/handle/ufscar/3152/5634.pdf?sequence=1\&isAllowed $=\mathrm{y}>$. Acesso em: 05 abr. 2017.

ROCHA-OLIVEIRA, Rafaela; DIAS, Viviane Borges; SIQUEIRA, Maxwel. Formação de Professores de Biologia e Educação Inclusiva: indícios do Projeto Acadêmico Curricular. Revista Brasileira de Pesquisa em Educação em Ciências, 19, 225-250, 2019. Disponível em: https://periodicos.ufmg.br/index.php/rbpec/article/view/4935/9958 . Acesso em 1 mar.2020.

SKLIAR, Carlos (Org.). Educação \& Exclusão: abordagens socioantropológicas em educação. 7. ed. Porto Alegre: Mediação, 2013.

SILVA, Luciene Maria da. O trato ético com a inclusão escolar em Sociedades administradas. Olh@ res, Guarulhos, v. 3, n. 1, p. 58-75. Maio, 2015. Disponível em: <http://www.olhares.unifesp.br/index.php/olhares/article/viewFile/316/119>. Acesso em: 27 set. 2016.

SILVA, Luciene Maria da. A deficiência como expressão da diferença. Educação em Revista, Belo Horizonte, v.44, p. 111-133, dez. 2006. Disponível em: <http://www.scielo.br/pdf/edur/n44/a06n44.pdf >. Acesso em: 29 mar. 2017.

SIMÕES, Maria Cristina Dancham. C. D. Formação do indivíduo, formação docente e educação especial: o lugar do sujeito e o compromisso com a adaptação. Tese de doutorado. Pontifícia Universidade Católica de São Paulo (PUC/SP). São Paulo, 2016. Disponível em: $<$ https://tede2.pucsp.br/bitstream/handle/19119/2/Maria\%20Cristina\%20Dancham\%20Sim\% C3\%B5es.pdf>. Acesso em: 25 maio 2017.

SOUZA, Sirleine Brandão de. A formação de professores na perspectiva da Inclusão de alunos com deficiência no ensino regular: análises de propostas curriculares de cursos de formação de professores no ensino superior no Estado de São Paulo. Dissertação de Mestrado em Educação: História, Política e Sociedade. Pontifícia Universidade Católica de São Paulo. 2013. Disponível em:

<https://sapientia.pucsp.br/bitstream/handle/10425/1/Sirleine\%20Brandao\%20de\%20Souza.p df>. Acesso em: 10 fev. 2015.

VILELA, Rita Amélia Teixeira. Críticas e possibilidades da educação e da escola na contemporaneidade: lições de Theodor Adorno para o currículo. Educação em Revista, Belo Horizonte, v. 45. p. 223-248. jun. 2007.Disponível em: <http://www.scielo.br/pdf/edur/n45/a12n45.pdf>. Acesso em: 20 mar. 2017.

VITALIANO, Célia Regina. Análise da necessidade de preparação pedagógica de professores de cursos de licenciatura para inclusão de alunos com Necessidades educacionais especiais. Rev. Bras. Ed. Esp., Marília, Set.- Dez. 2007, v.13, n.3, p.399-414. Disponível em: <http://www.scielo.br/pdf/rbee/v13n3/a07v13n3.pdf>. Acesso em: 26 maio 2016.

VITALIANO, Célia Regina; DALL'ACQUA, Maria Júlia Canazza; BROCHADO, Sônia Maria Dechandt. A disciplina Língua Brasileira de Sinais nos currículos dos cursos de Pedagogia. B. Tec. Senac, Rio de Janeiro, v. 39, n.2, p.106-121, maio/ago. 2013. Disponível em: <http://www.bts.senac.br/index.php/bts/article/view/351/335>. Acesso em: 07 jul. 2017. 


\section{SOBRE AS AUTORAS:}

\section{Viviane Borges Dias}

Doutora em Educação e Contemporaneidade pela Universidade do Estado da Bahia (UNEB); Professora da Universidade Estadual de Santa Cruz (UESC), credenciada ao Programa de PósGraduação em Educação em Ciências e Matemática (PPGECM/UESC); Membro do Grupo de Pesquisa Inclusão e Sociedade - UNEB e do Grupo de Pesquisa Currículo e Formação de Professores em Ensino de Ciências - GPeCFEC/UESC. E-mail:vbdias@uesc.br

(iD https://orcid.org/0000-0003-4528-5110

\section{Luciene Maria da Silva}

Doutora em Educação pela Pontifícia Universidade Católica de São Paulo (PUC/SP); Professora da Universidade do Estado da Bahia (UNEB), credenciada ao Programa de Educação e Contemporaneidade (PPGEduC); Coordenadora do Grupo de Pesquisa Inclusão e Sociedade (UNEB).E-mail: lmsilva@uneb.br

(iD https://orcid.org/0000-0001-5319-0467 